\title{
Conception, Technology and Methods of Development of University System of Innovation Projects Commercialization Based on Effectuation
}

\author{
Vladimir Dmitrievich Kolychev ${ }^{1} \&$ Igor Venyaminovich Prokhorov ${ }^{1}$ \\ ${ }^{1}$ National Research Nuclear University MEPhI, (Moscow Engineering Physics Institute), Russian Federation \\ Correspondence: Vladimir Dmitrievich Kolychev, Kashirskoye highway, 31, Moscow, 115409, Russian \\ Federation. E-mail: kolychev@mephi.ru
}

Received: November 19, 2014 Accepted: December 26, 2014 Online Published: March 20, 2015

doi:10.5539/ass.v11n8p44

URL: http://dx.doi.org/10.5539/ass.v11n8p44

\begin{abstract}
This paper is concerned with the problems of effectuation using innovation management for high-tech start-ups in the case of MEPhI. As a rule we are talking about successful projects developing in University context taking into consideration methods of effectuation and tutoring for their finalization. The object of investigation is the innovation project life-cycle development methods applied to the effectuation methods and techniques.

Using effectuation approach we could tell also about life-cycle of successful small and medium enterprises based on innovation project's development using some technologies of effectuation on each stage of life-cycle. The correct and appropriate methods of effectuation are important for venture investment's decision making in uncertain environmental conditions.

The authors are proposed some improved methods of commercialization process of perspective innovative projects in the context of effectuation.

Taking into account the author's experience in innovation projects commercialization, some methods of promotion and successful innovations planning in the case of ectuation are considered.
\end{abstract}

Keywords: effectuation, ectuation, commercialization, project's life-cycle, innovation management, promotion, forecasting, foresight, tutoring, educational system, IP (intellectual property)

\section{Introduction}

\subsection{Definition of Effectuation}

Effectuation could be recognized as logic of thinking as based on entrepreneurial activity and scientific researches using experts experience in entrepreneurship for creation of successful venture projects. (Sarasvathy, 2003). Some leader experts are recognizing effectuation as one of the most effective methods of scientific-oriented approach to business creation and entrepreneurial persons growing (Sarasvathy et al., 2014).

Making some efforts to successful idea realization entrepreneurs are not always able to observe a number of really effective methods of effectuation. Methods of effectuation help entrepreneurs and other stakeholders to assess future business and its attractiveness but in future. We consider that some methods of effectuation could be successfully implemented into the educational process in some disciplines on the innovation management and entrepreneurship to grow alertness in students and effective business idea planning (Dew et al., 2009).

Effectuation by our opinion is very close to the theory of entrepreneurship and management taking into consideration best practices of successful innovation projects commercialization (Read et al., 2009). Based on conception of effectuation really innovative methods of education are developed nowadays. By our opinion this direction is very fruitful especially in future growing uncertainty markets, for expenses reductions and profits growing.

We consider that it is possible to develop effective system of effectuation in the case of University for fast innovation growing spin-offs development and therefore the competitiveness and ranking of University increasing.

But it is necessary to accurately embed effectuation methods into the system of innovations development and 
commercialization of the University. We consider the implementation of the project-oriented approach to innovation management using systems analysis methods in life-cycle investigation issues.

\subsection{Effectuation Experience in Universities}

By the authors of this article experience it could be noted that entrepreneurial universities are making strong and sustainable policies and mechanisms for the entrepreneurship development, spin-off creation, consulting services for start-ups teams.

Considering universities as the centers of knowledge, spin-offs creation and effectuation we make announcement the importance of high-tech start-ups creation process in the context of universities network.

It is possible to observe best practices of innovation project creation and commercialization in the cases of leader innovation European Universities. The successful schemes of commercialization process are created in European Universities taking into consideration law and IP policies and regional specificity of each country.

For example in Cambridge University there are some entrepreneurial structures involved into knowledge effectuation, start-ups creation, commercialization and enterprises development in the Universities context. In Cambridge such structure has name of "Cambridge Enterprise" which involves techno-park, innovation infrastructure and IP distribution centre. The comparable situation could be observed in the Metropolitan University of London, but there using IP is minimized.

Also the Chinese polytechnic university creates its innovative infrastructure using venture funds and financing programs of government for fast innovation growing enterprises.

The authors are very familiar with Twente University innovation infrastructure, for example Venture Lab International, Technopark, Business Incubator. There are a lot of scouting and screening methods and programs of young entrepreneur's attraction (summer schools, classes, workshops, entrepreneurial weekends etc.). It is also possible to depicture the situation with innovation management and entrepreneurship in Groningen University, The Netherlands. The innovative infrastructure of Groningen University is also very diverse. There are special structures such as incubator, Green Lab and Living Lab Energy which are attracting mostly perspective students for master thesis development using effectuation methods of research, teaching and marketing development under uncertainty.

We are also able to use the experience of Nanyang Technical University (Singapore), which applies some entrepreneurial practices in effectuation and innovation management using educational and entrepreneurial policies.

In the case of MEPhI we can point out that nowadays there are a lot of modifications in the University policies, developed mechanisms and methods of innovation management.

For example, there are some competitive sessions of students in business R\&D planning projects creation using entrepreneurial ideas and effectuation methods. Some students of Institute of innovation management were among the winners of this competitive tour over Moscow Universities in 2013.

Moreover MEPhI now is creating the quantitatively new entrepreneurial structures such as Youth Engineering Center for development of SME in the territory of University.

\section{Methods of Investigation}

\subsection{Some General Issues in Innovation Projects Development and Implementation}

These issues are concerned mostly with organizational problems of entrepreneurs (Chandler et al., 2011). But by our opinion the most important problem of innovation projects commercialization is lying in the sphere of inexperienced researchers and project team members (may be even in the project team founders). The scientists who want to become the entrepreneurs must be involved in the organizational activity and theoretically must be experienced in administrative practices, but in practice the scientists, as a rule, are usually inexperienced in managerial methods.

After the innovative project foundation the scientists stops to be intensively involved in researches and must take a couple of time to business administration (project results forecasting, resources planning, production system management, value creation and assessment, quality management etc.).

Unfortunately this process of self-experienced education is last-longing and delaying in time. That is the effectiveness and rapidness of project commercialization and implementation will be substantially decelerated (Kolychev \& Prokhorov, 2014).

Also we must note that successful R\&D is usually developed by experienced entrepreneurs. Therefore it is 
important to involve some experienced persons for teaching, consulting and couching for the effectuation techniques training included into the branches of educational trajectory of entrepreneurs in their university.

\subsection{Methods of Commercialization Using Effectuation Technologies}

One of the effectuation method output for the scientists is based on intellectual property management. The most important issue in effectuation results in IP protection policy for innovation project management. Entrepreneurial oriented scientists must organize IP registration procedures using Universities policies and instruments of protection and support. IP level of small enterprises as it is well-known must be near (approximately equal) to the $80 \%$ of total assets of the firm. The IP results obtained from small enterprises could be presented as outputs of the scientific and research activity of the University. It could be review as one of the qualitative indicators of scientific researches.

That is effectuation usually results in intellectual assets of the University and supports it to be really innovative, entrepreneurial and competitive in the world level, helping to attract experts from all over the world in the sphere of innovation management.

It is possible to use effectuation methods in the special structures of Universities aimed on the innovation project commercialization.

In the functions of this structure except traditional coachers, mentors, tutors and trainers could be included entrepreneurs with broad experience of economic activity. Among their functions are some additional activities such as:

Patenting of scientific and researches results;

Enterprise and business development;

Team foundation including specially attracted students (preferably if they will be from the staff of special university center);

Creation of product prototype.

From the scientist point of view it is necessary to have only the project idea. After that the scientist makes his IP registration and passes all rights to the special structure of the University.

\subsection{The Scheme of Effectuation in the Case of University Commercialization System}

We think that the most effective methods of effectuation are lying in the sphere of screening process through the students of fours or fifth year of education as from technical faculties as cybernetics and management departments (Brettel et al., 2012).

It is possible to gather different suggestions and offers from innovative oriented students for choosing the most viable ideas. This process must hold under the guidance of experienced entrepreneurs and institution managers directed by the board of University leaders. After the knowledge effectuation and IP protection procedures it is possible to start production certification and enterprise development. System of MEPhI effectuation could be presented with the help of Figure 1.

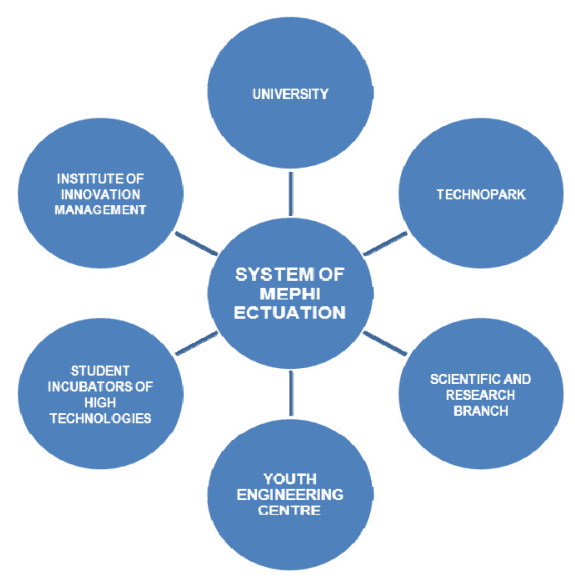

Figure 1. System of MEPhI effectuation 
We can depicture the scheme of commercialization process interrelated with effectuation technology with the help of such picture Figure 2.

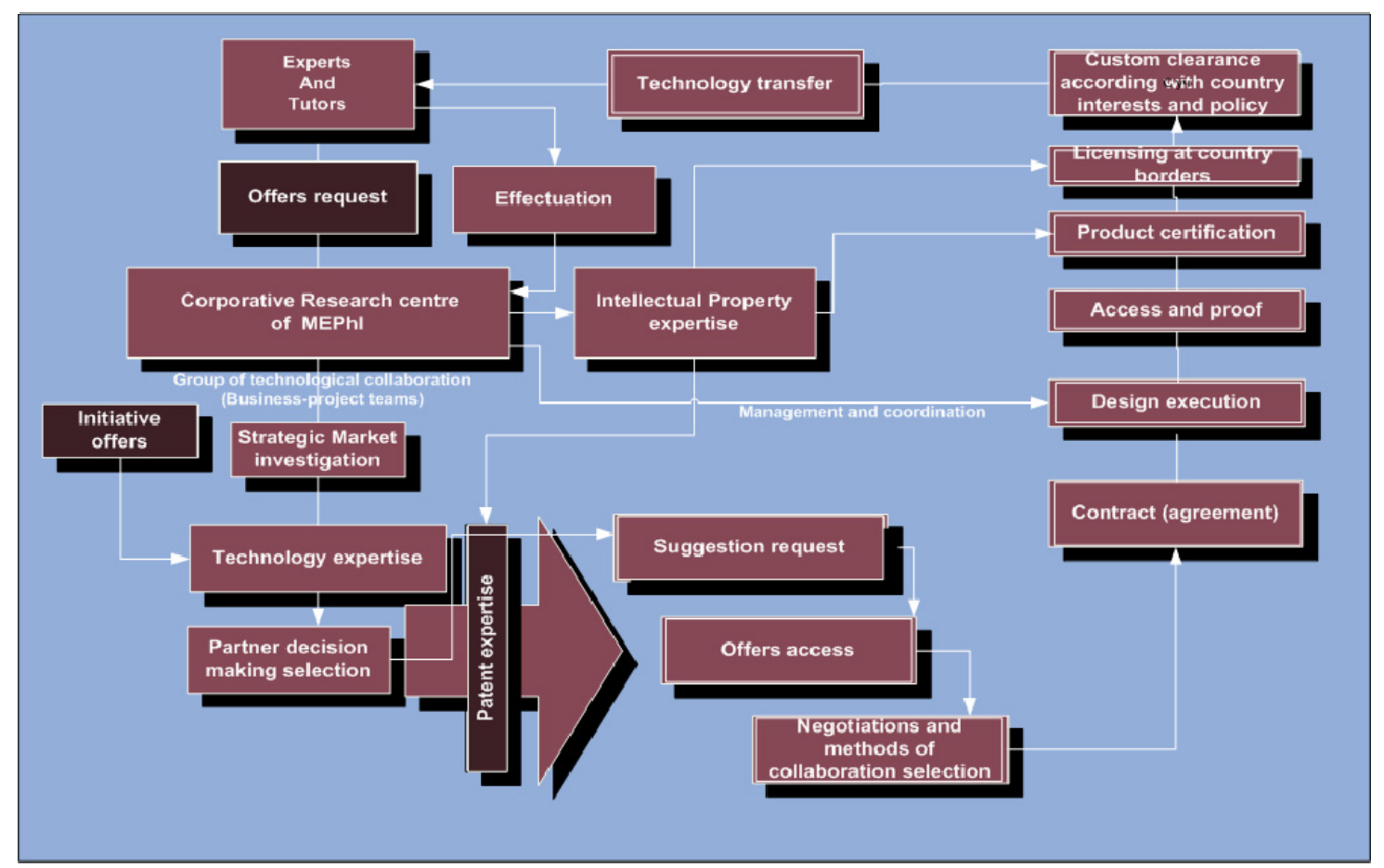

Figure 2. Scheme of effectuation and commercialization process in the case of MEPhI

\subsection{Innovation Project's Life-cycle and Knowledge Effectuation}

By our opinion it is possible to incorporate the stages of innovation project's life cycle and effectuation process enveloping in the time scale (frames), Figure 3. The project's life-cycle model helps researches to visualize the stages of commercialization process (Kolychev \& Rumyantsev, 2014). It is possible to review the life-cycle model under the angle of framework for developed managerial models and approaches to effectuation in the case of high-tech innovation projects. It is extremely important to choose appropriate instruments for modeling of life-cycle process corresponding with project's time line and purposes (Behrens \& Hawranek, 1991). Proposing some experience and best practices concerning with innovation projects realization it is possible to construct common framework for project analysis using effectuation methods and approaches.

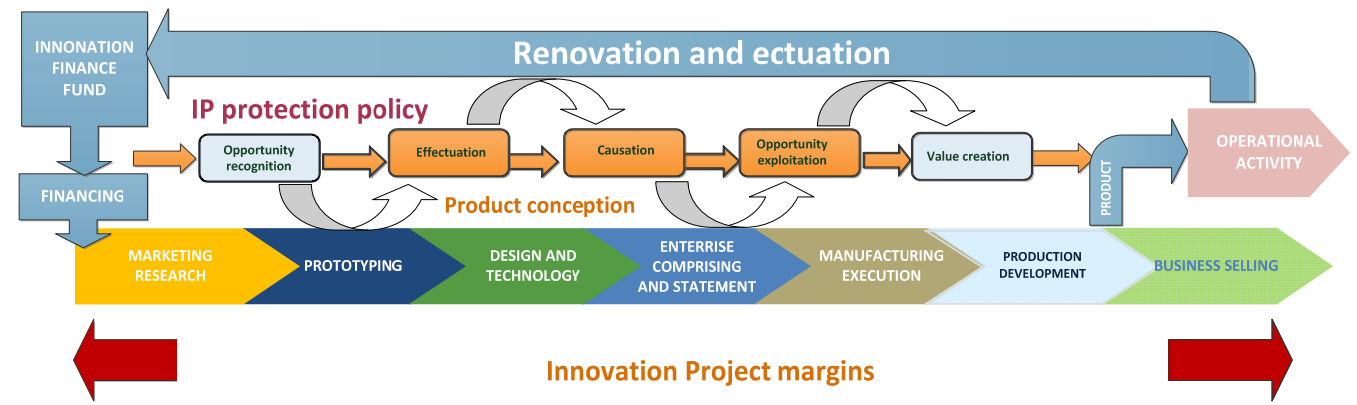

Figure 3. Innovation project life-cycle and effectuation process

In each stage of innovation project life-cycle it is possible to use different methods of effectuation (Uecke, 2010). The base instruments of effectuation helps entrepreneurs to recognize at each stage of life-cycle the appropriate ways of thinking and making their activities for better results and value creation. Moreover being correlated project management techniques (Duening et al., 2015) and effectuation methods gives double effective 
productivity and effectiveness (Kalinic et al., 2014) in the terms of life-cycle processes (Kolychev \& Rumyantsev, 2014).

\section{Results}

\subsection{Education System Concerning with Effectuation}

For the deployment of the process of real enterprise creation it is necessary to use the resources of University especially the groups of innovatively oriented students with developed marketing and project management competencies (Donnellon et al., 2014).

Some of such skills or competencies could be developed using effectuation education methods (Teerijoki \& Murdock, 2014).

For such kind of training methods could be used business games practices, case-oriented educational approaches, active methods of education and training, video conferences, webinars with prominent entrepreneurs.

We can suggest such kind of effectuation scheme in the sample cases used in Institute of Innovation Management based on small R\&D groups training in the laboratory on innovation management and entrepreneurship. We can demonstrate the knowledge effectuation in atomic problematic sphere based on researches and tutoring in Institute of Innovation Management at NRNU MEPhI.

Among the general activities of students during effectuation case-studies are:

Advertising of innovation project;

Project potential assessment;

Business - planning;

Innovation project management;

Marketing research;

Project IT support;

Diffusion in the neighbor spheres of business;

Project idea scaling;

Financial project management and evaluation;

Business idea presentation;

Patent and IP researches.

\subsection{Effectuation in the Case of MEPHI}

It is possible to show the role of educational and training methods in the process of effectuation in the case of NRNU MEPhI, Figure 4.

We consider that such kind of educational activity help to provide some effectuation activities and transform the routine procedures of knowledge acquisition into the business-games format especially for technical-oriented trajectories of teaching (Read et al., 2009).

Aiming into the knowledge effectuation in atomic sphere in the case of NRNU MEPhI some experts from real enterprises are attracted for their participation in the process of team development, IP registration, business administration and management, production planning, manufacturing, resources planning and acquisition (Lutters \& Houten, 2014). Therefore the special entrepreneurial team is constructed with the help of effectuation approach (Child \& Hsieh, 2014).

There are a lot of courses in educational program of Institute of Innovation Management of NRNU MEPhI concerning with practical issues of innovation management and entrepreneurship aimed into effectuation technology.

For example, some essential effectuation problems are discussed in the cases of real-state innovation projects:

Smart house management;

The nitrate sensor;

Water purifying systems;

Ion gas detectors;

Spectroscopy devices development; 


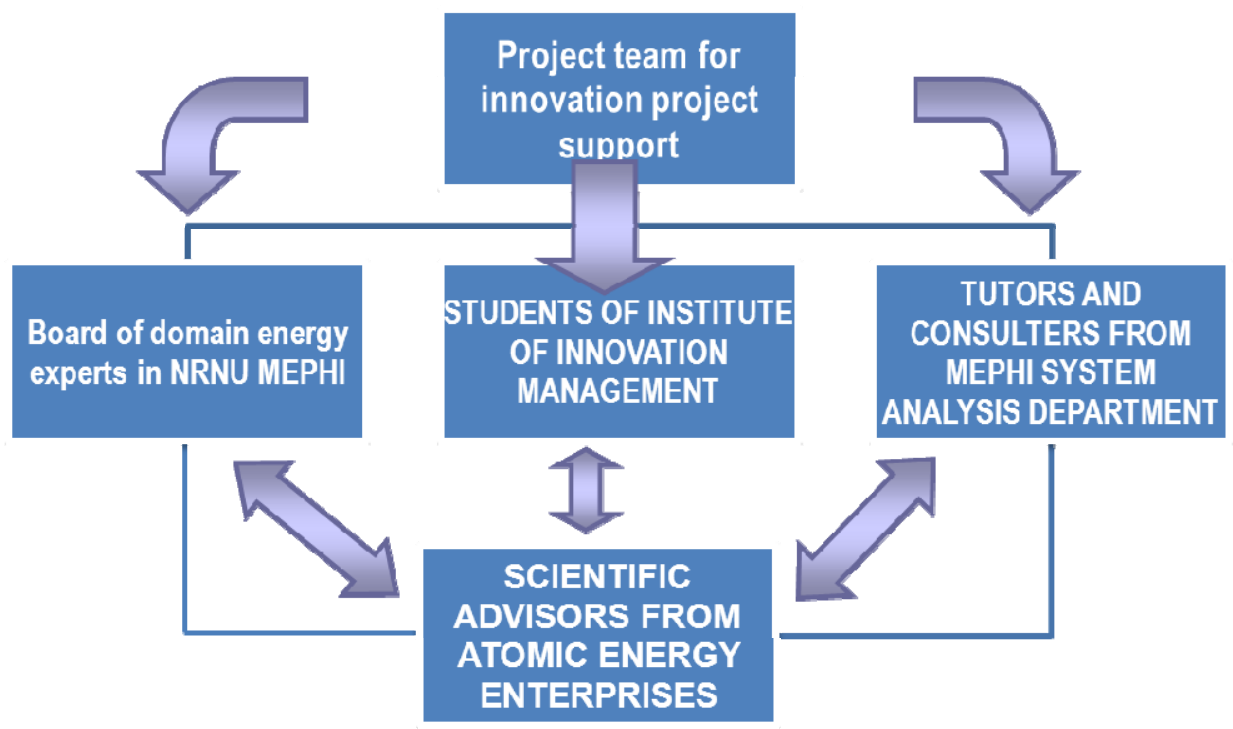

Figure 4. Scheme of effectuation in the case of NRNU MEPhI innovation projects development

\section{Discussion}

By our opinion it is important to develop the system of commercialization of university based on effectuation methods according with best practices of leader Universities as in EU and also in Asia. The authors experience concerning with observe of best practices of effectuation in China for example gives strong impetus for development of technologically sophisticated system which includes IP protection policy, developed mechanisms of internationalization, communication, socialization across dispersed virtual project teams (as in the case of $R \& D$ projects between leader research programs in Universities of Asian countries such like Singapore, Malaysia, Nyanja, China etc.).

The authors are in the discussion process with their Dutch colleagues (Groen, 2005; Groen et al., 2007) about development strong system of technology and knowledge effectuation system in the case of MEPHI. Incorporating with Delft University in Holland in the sphere of atomic reactors development and teaching students of technical specialties we acquired best practices of knowledge commercialization and effectuation in the case of nuclear knowledge and technologies. Moreover we suggest the technology of commercialization in the case of MEPHI based on project-oriented approach, business-games, team composing methods, virtual structures applying to the process of commercialization and technology transfer through margins of countries, states, regions and Universities (Breslina \& Jones, 2014).

Our experience in realization of common activities in international projects (such as (International Youth Scientific-Educational Project (Atomic Collaboration XXI) under the guidance of Rosatom and Commonwealth of Independent States - CIS) makes us assured within the aims of effectuation in the case of MEPHI. These aims contain the following goals:

Diversification of scientific and educational communications of nuclear industry young specialists of the countries - members of the Commonwealth with top foreign specialists in corresponding spheres of interests in the reference with their practical activity conditions and skills.

Consolidation of the international collaboration in the sphere of atomic educational technologies.

Distribution of the international academic standards at the all spheres of atomic youth education, including master courses using innovation management technologies in the Nuclear energy sphere.

Creation and foundation of the global youth nuclear community of CIS as a strategic resource of the progress, innovation development and modernization of the technological base of the Atomic energy field of the CIS.

\section{Conclusions}

In this paper the authors are presented their approach and understanding of effectuation process concerning with educational methods and techniques and also with general issues of innovation management and 
entrepreneurship.

The authors described their experience in this problematic area using examples of similar effectuation methods in other universities as Dutch, European and Asian.

It is possible to develop the model of effectuation using innovation project's life-cycle processes conception.

In the case of NRNU MEPhI it was described the system of commercialization and innovation management oriented on the effectuation process.

It was designated some issues of traditional innovation management team building and R\&D projects implementation. We are able to show the role of effectuation in the process of innovation project commercialization.

The best practices in educational sphere which are interrelated with effectuation methods were described.

\section{Acknowledgments}

The results of researches being done in MEPhI during several years on this problematic area were presented at High Tech Small Firms Conference (HTSF 2014) hold in Twente University the Netherlands in June 2014.

The authors acknowledge receiving recommendations and support from their colleagues from Dutch Institute for Knowledge Intensive Entrepreneurship (NIKOS) of the University of Twente, Enschede, the Netherlands for all years from 2006 up to the present time. We are responsible for all errors as well as heavy style of the article.

\section{References}

Behrens, W., \& Hawranek, P. M. (1991). Manual for the preparation of industrial feasibility studies (p. 386). Newly revised and expanded edition. United Nations Industrial Development organization. Vienna.

Breslina, D., \& Jones, C. (2014). Developing an evolutionary/ecological approach in enterprise education. The International Journal of Management Education, 12(2), 443-444.

Brettel, M., Mauer, R., Engelen, A., \& Küpper, D. (2012). Corporate effectuation: Entrepreneurial action and its impact on R\&D project performance. Journal of Business Venturing, 27(2), 167-184. http://dx.doi.org/10. 1016/j.jbusvent.2011.01.001

Chandler, G. N., DeTienne, D. R., McKelvie, A., \& Mumford, T. V. (2011). Causation and effectuation processes: A validation study. Journal of Business Venturing, 28(3), 375-390. http://dx.doi.org/10.1016/j.jbusvent.2009. 10.006

Child, J., \& Hsieh, L. H. Y. (2014) Decision mode, information and network attachment in the internationalization of SMEs: A configurational and contingency analysis. Journal of World Business, 49(4), 598-610. http://dx.doi.org/10.1016/j.jwb.2013.12.012

Dew, N., Read, S., Sarasvathy, S. D., \& Wiltbank, R. (2009). Effectual versus predictive logics in entrepreneurial decision-making: Differences between experts and novices. Journal of Business Venturing, 24(4), 287-309. http://dx.doi.org/10.1016/j.jbusvent.2008.02.002

Donnellon, A., Ollila, S., \& Middleton, K. W. (2014). Constructing entrepreneurial identity in entrepreneurship education. The International Journal of Management Education, 12(3), 490-499. http://dx.doi.org/10.1016 /j.ijme.2014.05.004

Duening, T. N., Hisrich, R. D., \& Lechter, M. A. (2015). Chapter 1 - Technology Entrepreneurship Today: Trends, Opportunities, Challenges. Technology Entrepreneurship (2nd ed.). Taking Innovation to the Marketplace, 3-16. http://dx.doi.org/10.1016/B978-0-12-420175-0.00001-4

Groen, A. J. (2005). Knowledge intensive entrepreneurship in networks: Towards a multi-level multi-dimensional approach. Journal of Enterprising Culture, 13(1), 69-88. http://dx.doi.org/10.1142/S0 218495805000069

Groen, A. J., Kraaijenbrink, J., \& Heuven, J. (2007). Towards a neo-social systems theory of the firm. Annual meeting of the academy of management. Philadelphia.

Kalinic, I., Sarasvathy, S. D., \& Forza, C. (2014). "Expect the unexpected”: Implications of effectual logic on the internationalization process. International Business Review, 23(3), 635-647. http://dx.doi.org/10.1016/j. ibusrev.2013.11.004

Kolychev, V. D., \& Prokhorov, I. V. (2014). Application of road mapping for hi-tech projects commercialization in corporate innovative entrepreneurship. Ecology Environment \& Conservation, 20(4), 1895-1906. 
Kolychev, V. D., \& Rumyantsev, V. P. (2014). Specificity of the product's life-cycle management models. Non-ferrous metals, 2, 3-7.

Kolychev, V. D., \& Rumyantsev, V. P. (2014). Visual models' system of project management. Scientific Visualization, 6(3), 14-54.

Lutters, E., Houten, F. J. A. M., Bernard, A., Mermoz, E., \& Schutte, C. S. L. (2014). Tools and techniques for product design. CIRP Annals - Manufacturing Technology, 63(2), 607-630. http://dx.doi.org/10.1016/j.cirp. 2014.05.010

Read, S., Dew, N., Sarasvathy, S. D., Song, M., \& Wiltbank, R. (2009). Marketing Under Uncertainty: The Logic of an Effectual Approach. Journal of Marketing, 73(3), 1-18. http://dx.doi.org/10.1509/jmkg.73.3.1

Sarasvathy, S. D. (2003). Entrepreneurship as a science of the artificial. Journal of Economic Psychology, 24(2), 203-220. http://dx.doi.org/10.1016/S0167-4870(02)00203-9

Sarasvathy, S., Kumar, K., York, J. G., \& Bhagavatula, S. (2014). An Effectual Approach to International Entrepreneurship: Overlaps, Challenges, and Provocative Possibilities. Entrepreneurship: Theory and Practice, 38(1), 71-93. http://dx.doi.org/10.1111/etap.12088

Teerijoki, H., \& Murdock, K. A. (2014). Assessing the role of the teacher in introducing entrepreneurial education in engineering and science courses. The International Journal of Management Education, 12(3), 479-489. http://dx.doi.org/10.1016/j.ijme.2014.05.005

Uecke, O., Rajendran, L., Schellin, S., \& Simons, K. (2010). Enhancing effectiveness in early stages of technology transfer and entrepreneurship: The case of a new Alzheimer's disease treatment. Conference paper for: 18th Annual High Technology Small Firms Conference (HTSF) May 27 \& 28, 2010, University of Twente.

\section{Copyrights}

Copyright for this article is retained by the author(s), with first publication rights granted to the journal.

This is an open-access article distributed under the terms and conditions of the Creative Commons Attribution license (http://creativecommons.org/licenses/by/3.0/). 